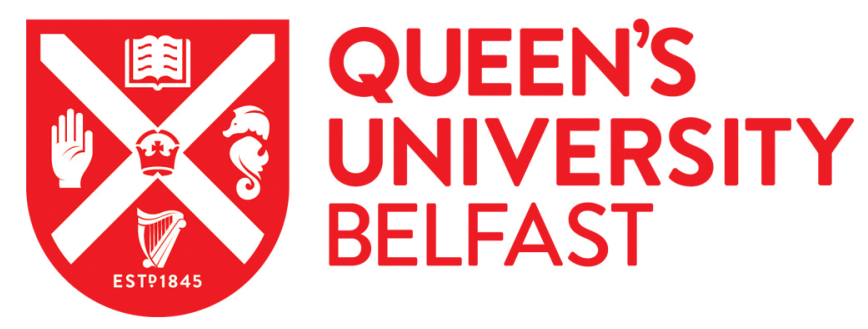

\title{
Development and field testing of a vision based displacement system using a low cost wireless action camera
}

Lydon, D., Lydon, M., Taylor, S., Martinez del Rincon, J., Hester, D., \& brownjohn, J. (2019). Development and field testing of a vision based displacement system using a low cost wireless action camera. Mechanical Systems and Signal Processing, 121, 343-358. https://doi.org/10.1016/j.ymssp.2018.11.015

Published in:

Mechanical Systems and Signal Processing

Document Version:

Peer reviewed version

Queen's University Belfast - Research Portal:

Link to publication record in Queen's University Belfast Research Portal

Publisher rights

(C) 2018 Elsevier Ltd.

This manuscript version is made available under the CC-BY-NC-ND 4.0 license http://creativecommons.org/licenses/by-nc-nd/4.0/,which permits distribution and reproduction for noncommercial purposes, provided the author and source are cited

\section{General rights}

Copyright for the publications made accessible via the Queen's University Belfast Research Portal is retained by the author(s) and / or other copyright owners and it is a condition of accessing these publications that users recognise and abide by the legal requirements associated with these rights.

Take down policy

The Research Portal is Queen's institutional repository that provides access to Queen's research output. Every effort has been made to ensure that content in the Research Portal does not infringe any person's rights, or applicable UK laws. If you discover content in the Research Portal that you believe breaches copyright or violates any law, please contact openaccess@qub.ac.uk. 


\title{
Development and field testing of a vision-based displacement system using a low cost wireless action camera.
}

\author{
Darragh Lydon ${ }^{1}$, Myra Lydon ${ }^{1}$, Su Taylor ${ }^{1}$, Jesus Martinez Del Rincon ${ }^{2}$, David Hester ${ }^{1}$ \\ and James Brownjohn ${ }^{3}$
}

\author{
${ }^{1}$ School of Natural and Built Environment, Queens University Belfast, Northern Ireland. \\ ${ }^{2}$ School of Electronics, Electrical Engineering and Computer Science, Queens University \\ Belfast, Northern Ireland. \\ ${ }^{3}$ University of Exeter, United Kingdom. \\ * Corresponding author. Postal address: School of Natural and Built Environment, \\ Queens University Belfast, Northern Ireland \\ Phone number: +442890974025 \\ Email address: m.lydon@qub.ac.uk
}

\begin{abstract}
This paper describes development of a contactless, low cost vision-based system for displacement measurement of civil structures. Displacement measurements provide a valuable insight into the structural condition and service behaviour of bridges under live loading. Conventional displacement gauges or GPS based systems have limitations in terms of access to the infrastructure and accuracy. The system introduced in this paper provides a low cost durable alternative which is rapidly deployable in the field and does not require direct contact or access to the infrastructure or its vicinity. A commercial action camera was modified to facilitate the use of a telescopic lens and paired with the development of robust displacement identification algorithms based on pattern matching. Performance was evaluated first in a series of controlled laboratory tests and validated against displacement measurements obtained using a fibre optic displacement gauge. The efficiency of the system for field applications was then demonstrated by capturing the validated bridge response of two structures under live loading including the iconic peace bridge. Located in the City of Derry, Northern Ireland, the Peace Bridge is a $310 \mathrm{~m}$ curved self-anchored suspension pedestrian bridge structure. The vision-based results of the field experiment were confirmed against displacements calculated from measured accelerations during a dynamic assessment of the structure under crowd loading. In field applications the developed system can achieve a root mean square error (RMSE) of $0.03 \mathrm{~mm}$ against verified measurements.
\end{abstract}

Keywords: vision based displacements , bridge monitoring, field testing 


\section{Introduction and State of the Art}

Existing civil infrastructure is under continuous levels of stress from loading and environmental effects whose effects can be detrimental to the integrity of the bridges, so that they must be monitored periodically to avoid dangerous incidents and ensure public safety. Visual inspections remain as the most common method of bridge inspection worldwide [1], is used as a means of detecting obvious damage to structures such as cracks/shifting of components, and is carried out by following a set of established guidelines according to bridge type. However, this approach has many limitations which affect reliability. The method is extremely sensitive to human error, particularly since a visual inspection is rarely carried out by a senior engineer hence it is limited by human capabilities, which means that small displacements and defects may pass unnoticed. A survey of the reliability of visual inspections has detailed the high level of variability in this assessment method [2].

Structural Health Monitoring (SHM) systems provide a valuable alternative to traditional inspections [3-6] and can provide an unbiased and precise means of determining the true state of aging infrastructure. SHM systems allow monitoring of the structural load and response over short periods or for long term, with commonly used sensors including both accelerometers and strain gauges, but there has recently been increased interest in using displacement measurements as a powerful means of assessing bridge condition through performance [7].

Displacement can be measured using traditional sensors, such as the linear variable differential transformer (LVDT), but these instruments require direct contact with the bridge structure to obtain measurements, which can be unfeasible or unsafe in certain scenarios. Accelerometers can also be used for dynamic displacement monitoring up to a point, but they are susceptible to numerical integration error[8]. Global Positioning System (GPS) based sensors can also be used for displacement calculation, but the accuracy of the system is not comparable to that of other systems, with the majority of commercial systems only capable of obtaining accuracy at the centimetre level [9]. Finally, laser vibrometers can provide an accurate measurement along the line of sight at single discrete points [10] but are expensive and cumbersome and do not provide flexibility of measurement available in conventional vision systems.

In recent years, Computer Vision techniques have been applied to the field of SHM, allowing conventional Charge-coupled device (CCD) cameras to be used, as is discussed in [11]. There are two prevalent algorithmic approaches for automatic displacement calculation: Digital Image Correlation (DIC)[12] where a pattern is applied to structures and the totality of this pattern is used as a reference to calculate displacement between frames; and feature-based registration methods [13] where reliable features are extracted from either an applied target pattern or from natural features of the bridge itself, e.g. rivets, irregularities in the concrete pour etc. These two methods are compared in [14]. 
Early work in this field is described in [15]. The authors attached two LEDs to a monitoring location on their bridge and used these as targets for their DIC-based system. The low resolution of the camera used in this test along with the necessity of using an attached LED to obtain results make it impractical for use on many types of bridges in service. This method was developed further in [16], where LED targets were used to obtain displacement of a bridge using a cross-correlation analysis to detect displacement of the affixed LEDs . Further examples of DIC-based methods are described in [17-19]. The main disadvantage is the use of attached targets which limit application to bridges where monitoring locations are accessible. In [20], the authors used a variety of algorithmic approaches including color pattern matching and mean shift tracking to determine displacement of bridges in the field. Additional examples of feature based displacement calculation using contact targets are described in [21] [22] and [23].

As camera equipment becomes more powerful and affordable, there has been a shift towards feature-based, target less methods for displacement estimation. This is shown by the work of [24], however the natural feature readings obtained in that paper are not subjected to any ground truth verification by traditional sensor or reference; only a comparison between readings of the camera are used. Further work was carried out in [25] where results comparable to LVDT were obtained at a distance of approximately $30 \mathrm{~m}$ using professional cameras. These readings are therefore useful for displacement calculation, but the requirement of having a laptop computer connected to the camera used for obtaining video images is not ideal to all locations.

The use of high resolution, durable low-cost action cameras, instead of professional cameras, has been initially explored in [26] but only in a lab trial for a small structure. This paper aims to continue this area of research, demonstrating that low-cost consumer grade cameras can be used effectively, by adding long range zoom capabilities to the action camera to provide greater flexibility in monitoring locations for bridge structures. This paper will also detail the integration of the modified low-cost cameras into an accurate, easy to use computer vision system for SHM which has been validated by laboratory trials and field experiments. Challenges that need to be overcome in the field of computer vision are that of counteracting environmental effects such as camera movement [27]. This paper will also detail laboratory trials carried out to ascertain the effect of this movement on displacement accuracy. The system reported here not only allows taking measurements in places where physical access is physically impossible or challenging, but also reduces mitigates personal risk in the field measurements.

\section{System Development}

The concept of vision-based displacement measurement is illustrated in Figure 1. In general, a camera is set up on a tripod at a stationary location in view of the bridge. The camera is used to record a series of images of a structural region or element of the bridge under live loading, usually at a minimum frame rate of 25 frames per second (fps). A 
significant advantage of the system is the ability to measure displacement at any location along the span of the bridge from one stationary camera location.

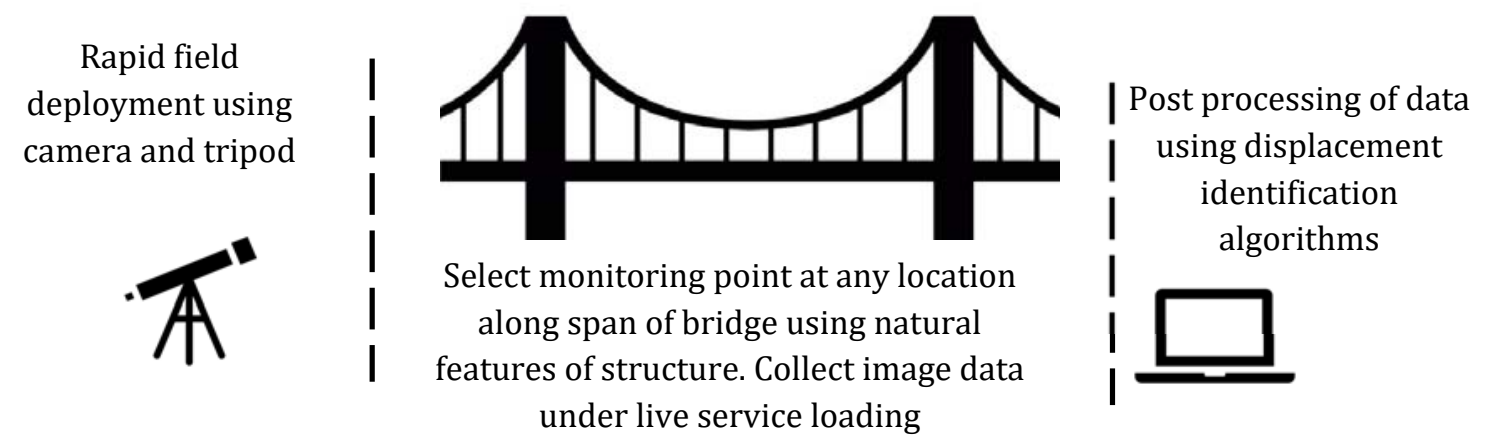

Figure 1: Vision based monitoring concept.

\subsection{Hardware configuration:}

It was decided to use GoPro action cameras [28] for capturing footage in this project as they are low-cost, high resolution (up to $4 \mathrm{~K}$ ), portable and provide wireless functionality for camera control. In addition, these cameras are resistant to adverse environmental conditions such as rain, making them practical for long term deployment in the field. The disadvantage of using GoPros for bridge monitoring is that the standard GoPro lens has a very short focal length, rendering them unsuitable for long distance monitoring of bridge structures. Research was carried out into possible modifications to the camera to add long distance monitoring capability; a solution was found using a modification kit for the GoPro: Ribcage[29](Figure 2). The Ribcage adds functionality for attaching C and Fmount zoom lens to a GoPro; this allows usage of the GoPro as a long-distance monitoring tool.

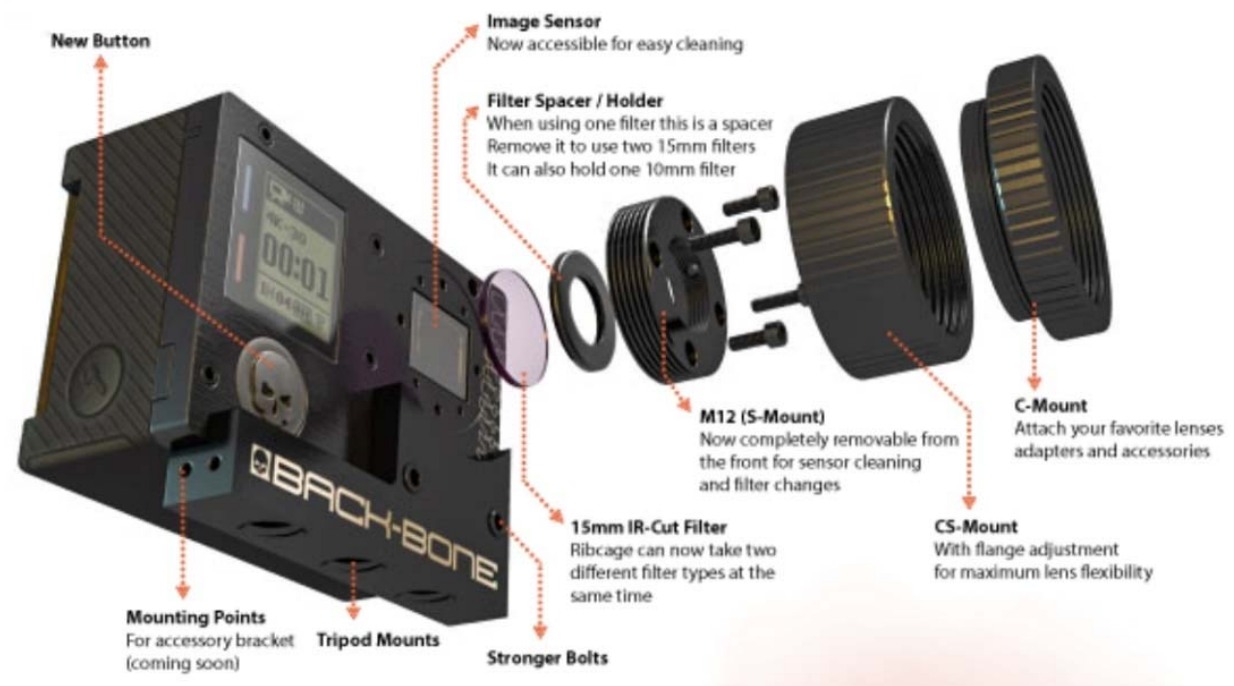

Figure 2 Ribcage Hardware Specification [30]

A low-cost Computar 1/2" 25-135mm F1.8 C-Mount lens [31] was attached to the GoPro for the testing (Figure 3) detailed in the following sections. The GoPro was controlled 
during testing using the Capture App[32] for smartphones provided by GoPro, with footage saved to microSD cards for later transfer to PC for post processing, removing the inconvenience and need for wiring between camera and processing devices inherent in other approaches.

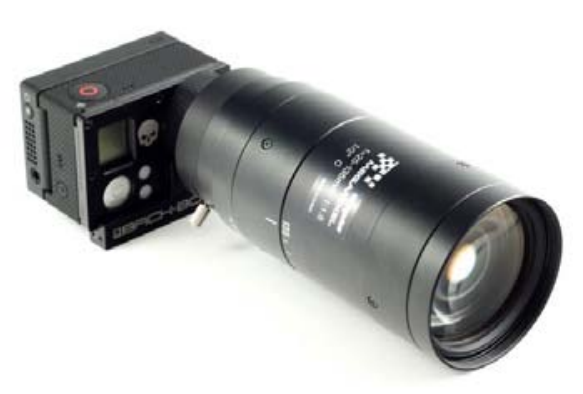

Figure 3 Modified GoPro with Zoom lens attached

\subsection{Development of Vision Based System:}

The development of all vison based SHM systems is dependent on intensive post processing algorithms [33] to convert the captured images into accurate bridge displacements.

A feature-based approach was chosen due to being more robust and reliable than DIC approaches[34] and, when paired with a reliable feature extraction technique, with similar precision. The processing framework is composed of three main blocks, as shown in Figure 4.

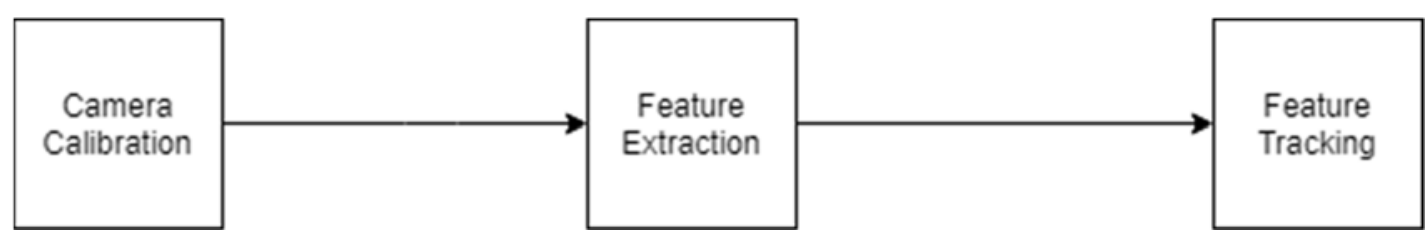

Figure 4 Block Diagram of Algorithm Design

Camera Calibration: Camera Calibration is a method of determining the intrinsic and extrinsic paramenters of the camera used to record the structure motion to remove lens distrortion effects and to provide a scaling factor for the conversion from pixel units to engineering units. The method used in removing lens distortion in this study was the one proposed by Bouguet in [35], where a series of images of a checkerboard or similar pattern is used to obtain the lens distortion of a camera at the desired focal length.

There are a variety of approaches used to determine the scaling factor for converting pixels to physical distance. In [36], a pre-testing calibration method is demonstrated. This involves setting up the camera in the laboratory in an identical manner to that of the 
field test to be carried out, i.e. same monitoring distance, focal length, angle etc. The camera is calibrated using the checkerboard pattern, and these variables are used to remove lens distortion and provide a scaling factor for the videos captured in the field trials. The formula to show this is written below in (1)

$$
S F=\frac{d}{D}=\frac{f}{p \times Z}\left(\frac{p i x e l}{m m}\right)
$$

SF is the scaling factor ratio, $d$ is a distance on the image, $D$ is a world distance, $f$ is the focal length of the camera, $p$ is the unit length of the camera sensor ( $\mathrm{mm} / \mathrm{pixel}$ ) and $Z$ is the distance from the camera to the monitoring location. The scaling factor can also be determined by use of the formula

$$
S F=\frac{D_{\text {Known }}}{I_{\text {Known }}}
$$

where $D_{\text {Known }}$ is the known physical length on the object surface and IKnown is the corresponding pixel length on the image plane.

Feature Extraction: This is the process of extracting/detecting salient features from the images of the object to be tracked. Examples of these could be corners, rivets or natural

decay in a concrete or steel structure. Processing time can be minimised by only searching for features inside a Region of Interest(ROI). The process selected for use in the algorithm was SURF[37], a robust and computationally inexpensive extension of SIFT[38]. The keypoints provided by SURF are scale and rotation invariant and are detected using a Haar wavelet approximation of the blob(region in an image that differ in properties such as brightness/colour from surrounding regions) detector based on the Hessian determinant. These approximations are used in combination with integral images(the sum of pixel values in the image) to encode the distribution of pixel intensity values in the neighborhood of the detected feature. The features detected in the laboratory tests are shown in

Figure 5.

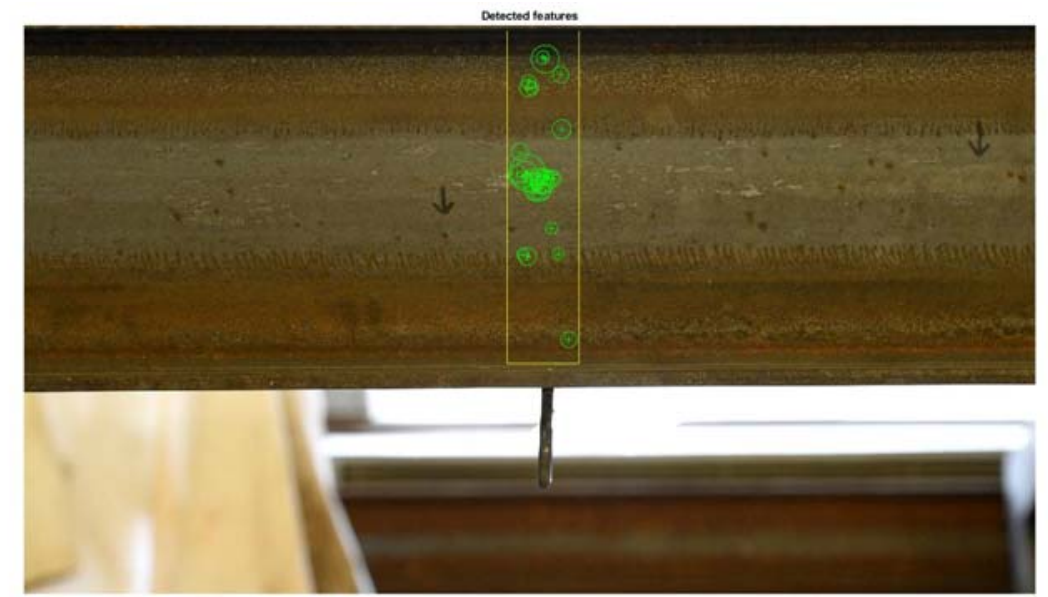


Feature Tracking: Once the points are detected, they must be tracked through subsequent frames to filter outliers and improve the displacement dynamic estimation. Careful application of threshold values must be maintained during this process, as features may become occluded or vary during the progression of a video. Our system makes use of a Kanade- Lucas Tomasi (KLT) [39] tracker to determine movement of the features detected. This method takes the points detected by the feature extractor and uses them as initialisation values. The system removes outliers using the statistically robust Mestimator SAmple Consensus (MSAC) algorithm[40]which is a variant of the RANSAC algorithm. The MSAC algorithm scores inliers according to the fitness to the model and uses this together with a user-specified reprojection error distance to minimize the usage of outliers in the displacement calculation. Any features that do not meet these thresholds are rejected, with the inliers then tracked on the next video frame using the KLT algorithm. The displacement of the object can be measured in pixels by calculating the relative movement between frames of the centroid of a matrix containing the extracted features. The pixel movement is converted to engineering units using the formula in Equation (2). This continues until all frames of the video have been processed.

This value can then be plotted with respect to another factor: e.g. Load or Time to evaluate the normal or abnormal behaviour of the piece of infrastructure.

\section{Experimental validation}

\subsection{Laboratory Trial 1 - Displacement Calculation}

The accuracy of the hardware system and associated post processing techniques were evaluated through a laboratory experimental program. This involved tracking the displacement of a centrally loaded $178 \mathrm{~mm} \times 102 \mathrm{~mm} \times 19 \mathrm{~mm}$ universal beam with a span of $5.3 \mathrm{~m}$ simply supported at each end and centrally loaded to induce displacement along the span of the beam. A Static load of $332 \mathrm{~kg}$ was applied to midspan of the beam for the test series. As shown in

Figure 6, 10 measurement points were identified at even spacing along the span of the beam, Nodes 1-10 (N1-10). A Fibre optic displacement gauge (FO) with a resolution of $0.03 \mathrm{~mm}$ was used at Node 7 to validate the accuracy of the camera readings. This Node was chosen as it was the closest available point to midspan (the point of maximum displacement) that the FO could be attached to due to interference from the load. The loading was applied in cycles where the load was slowly applied to the beam; this was then allowed to settle for at least 10 seconds and was then removed. This cycle was repeated 3 times for each FO node location. The camera was set up perpendicular to the beam, at a monitoring distance of $3.2 \mathrm{~m}$ in all tests and set to record continuously at a frame rate of 25 frames per second (fps). The data acquisition rate of the FO was set to $25 \mathrm{~Hz}$ to allow accurate comparison of the data. During the loading cycles, Node 7 was 
monitored at differing zoom settings to determine the effect on accuracy from changes to the scaling factor from Equation (2). In each case the FO provided a validated displacement measurement for N7. The loading cycle was repeated 3 times for each zoom setting of the camera.

\section{$5.3 \mathrm{~m}$}

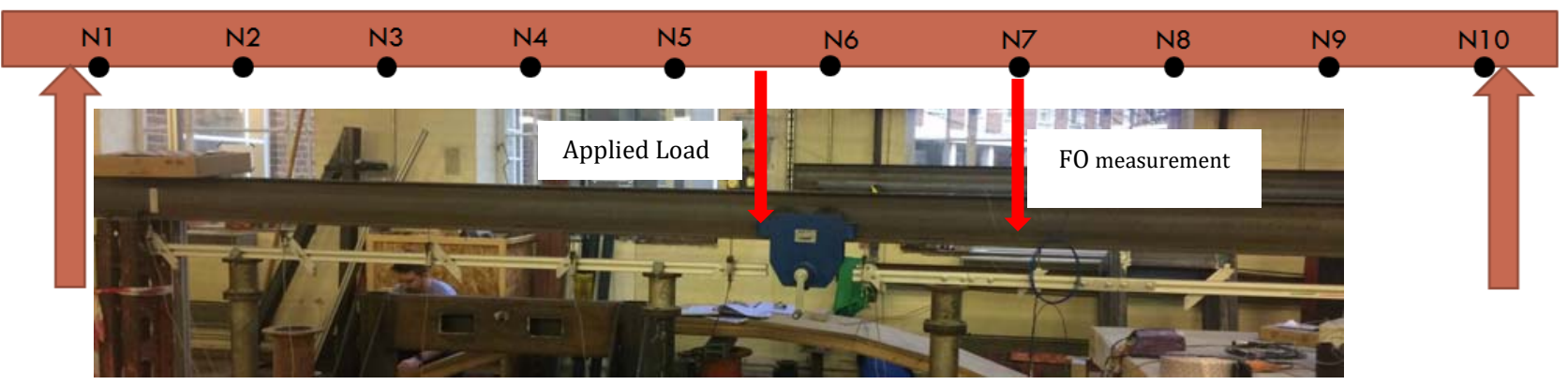

Figure 6 Testing and measurement arrangement

\subsubsection{Results}

The primary objective of this test plan was to validate the measurements of the camera for displacement monitoring in a controlled environment. As previously mentioned the FO was used as a ground truth for the camera data, the zoom setting on the action camera was varied to ascertain its influence on the accuracy of the calculated displacements; the staged zoom levels are presented in Figure 7. Levels 1-3 correspond to the vision-based monitoring of $\mathrm{N} 7$ at the differing zoom levels.
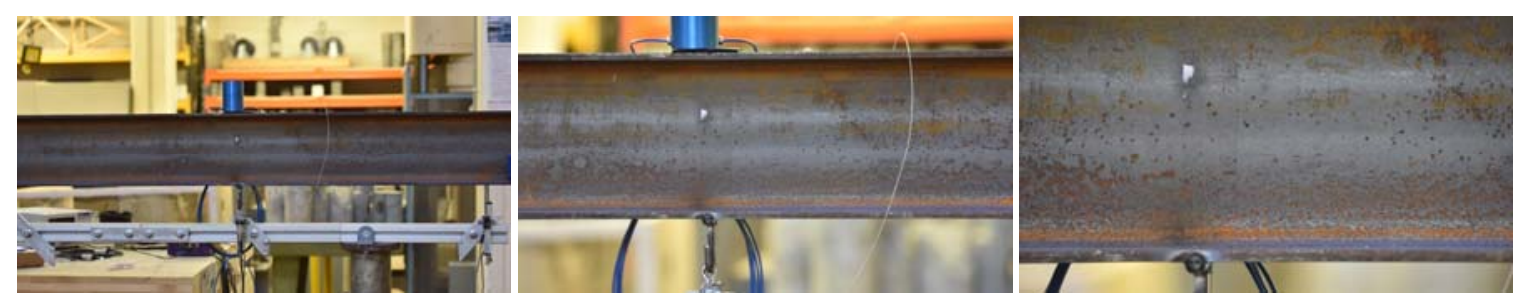

Figure 7 Testing and measurement arrangement

An increase in zoom level would result in an increase in accuracy of the algorithm due to the improvement in spatial resolution; it was desired to determine a threshold for accuracy for the system. The readings taken at each node were converted from pixel to $\mathrm{mm}$ using the scaling factor from (2). The results from the three loading cycles have been averaged for display in Table 1.

Table 1 Results from Tests at 3 different Zoom levels.

\begin{tabular}{cccc}
\hline Test & Nodes Monitored & Pixel/mm Scaling Factor & RMSE vs FO at Node 7 \\
1 & $7,8 \& 9$ & $0.7747 \mathrm{~mm}$ & 0.0713 \\
\hline
\end{tabular}




\begin{tabular}{cccc}
\hline 2 & $7 \& 8$ & $0.4519 \mathrm{~mm}$ & 0.0831 \\
3 & 7 & $0.1011 \mathrm{~mm}$ & 0.0434 \\
\hline
\end{tabular}

As can be seen from the table, there is a very small error between the camera system and the FO. Error! Reference source not found. show the results from performed tests. At the highest zoom setting (i.e. the lowest pixel: mm scaling factor), the proposed action camera system can achieve accurate displacement measurement of less than $0.1 \mathrm{~mm}$ at $3 \mathrm{~m}$, and with great accuracy in comparison to reliable but inconvenient FO sensors.

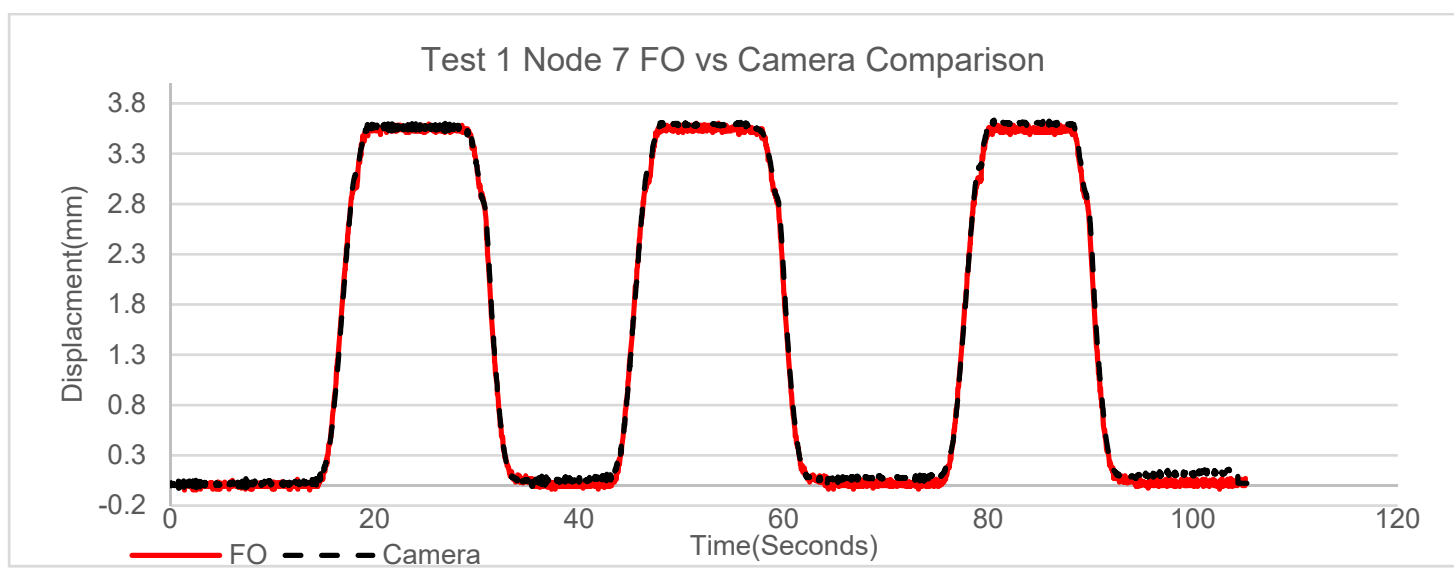

Figure 8 Results from Test 1 vs F0 at Node 7

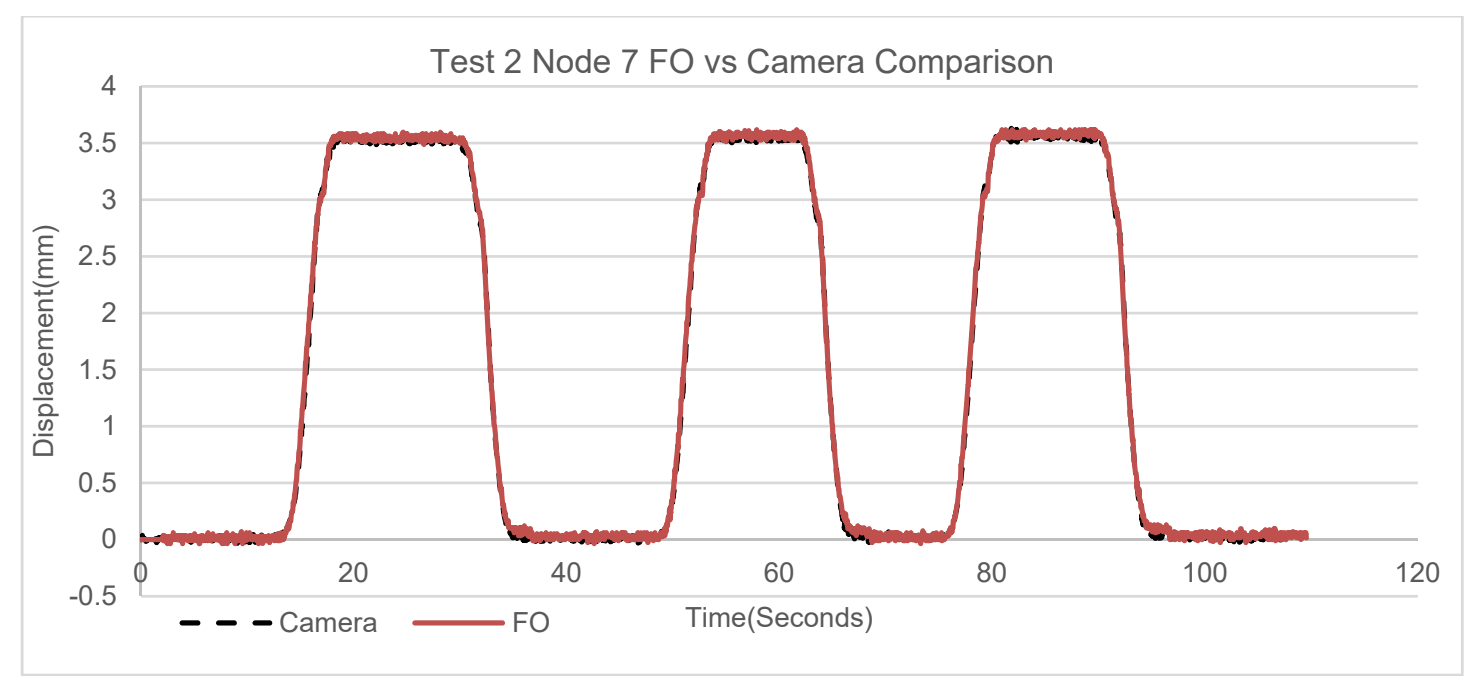

Figure 9 Results from Test 2 vs FO at Node 7 


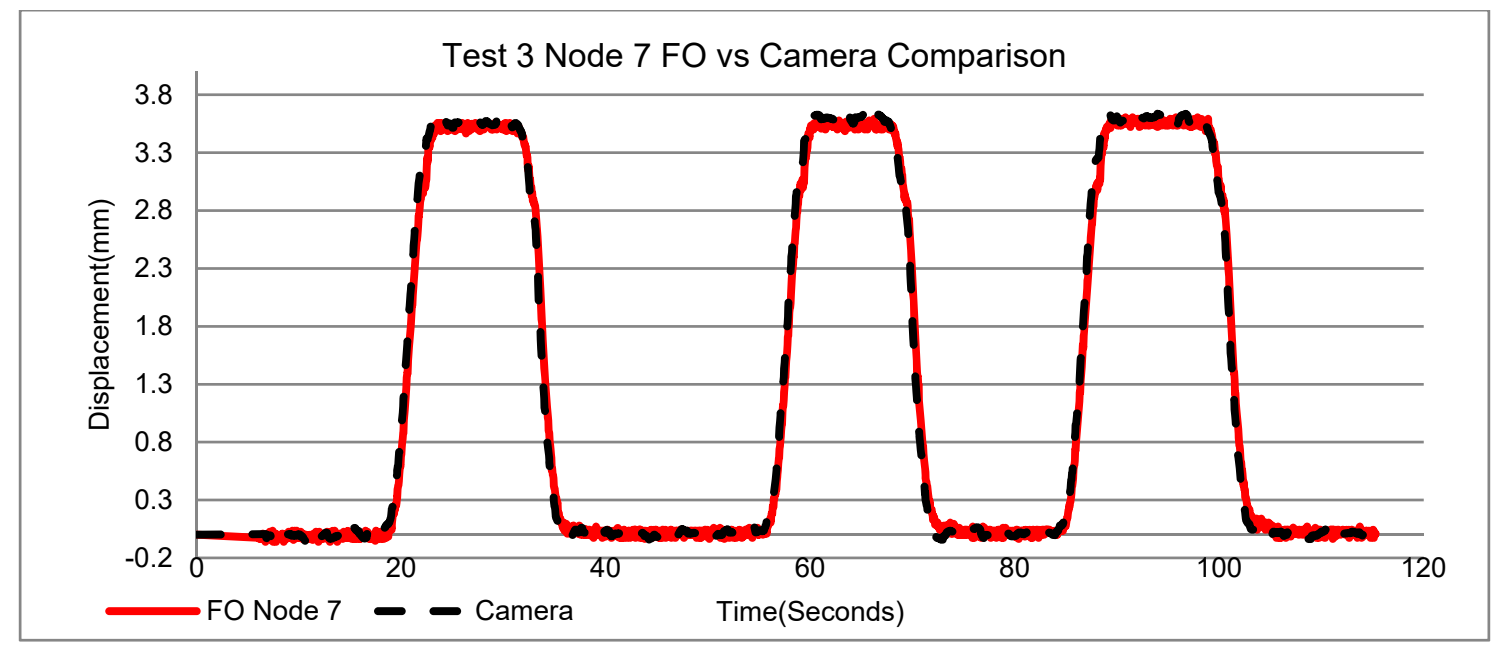

Figure 10 Results from Test 3 vs F0 at Node 7

The camera-based monitoring system has been validated at various zoom settings vs the FO. This has provided confidence in the usage of the system and proposed post processing algorithms as a means for determining displacement of a bridge structure in the field in a contactless, convenient, safe and low-cost manner.

\subsection{Laboratory Test Series 2: Camera Stabilisation Trials}

One of the difficulties to be overcome in the development of a computer vision-based system for displacement monitoring is that of environmental effects. One of the primary concerns is traffic vibration/wind moving the camera as monitoring is taking place. A trial was carried out in the laboratory to ensure this issue was resolved prior to field investigations.

\subsubsection{Camera Vibration Trial}

For this trial, the testing apparatus from Test Series 1 was used. The camera was set up $4 \mathrm{M}$ from the monitoring location and set to record at 25FPS, validation was provided by the FO at $25 \mathrm{hz}$. The camera was manually vibrated during the testing process to simulate the movement caused by traffic/wind under field conditions. A sample frame from this trial is shown in Figure 11. 


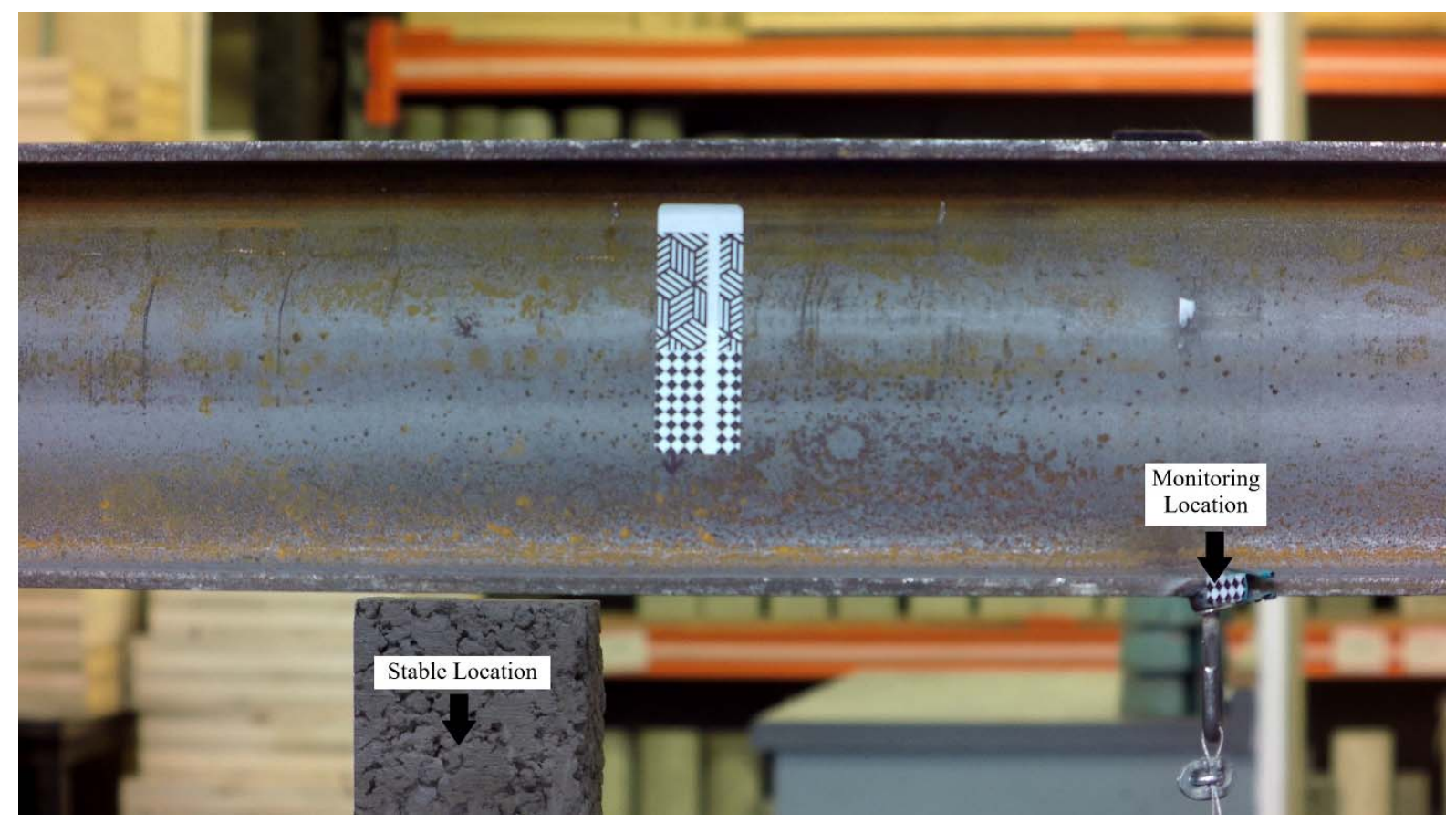

Figure 11 Sample Frame from Stabilisation Trial

The method used to remove camera vibration is laid out in [41]. A known stable location in the frame is used as an anchor point to correct for camera movement, in this case the concrete block shown above. The video is then processed using the algorithm detailed in the previous section, the displacement readings at the stable location are subtracted from those calculated at the monitoring location to give a corrected reading for 
displacement throughout the video. The results from this test are shown in Figure 12Error! Reference source not found. and summarised in Table 2.

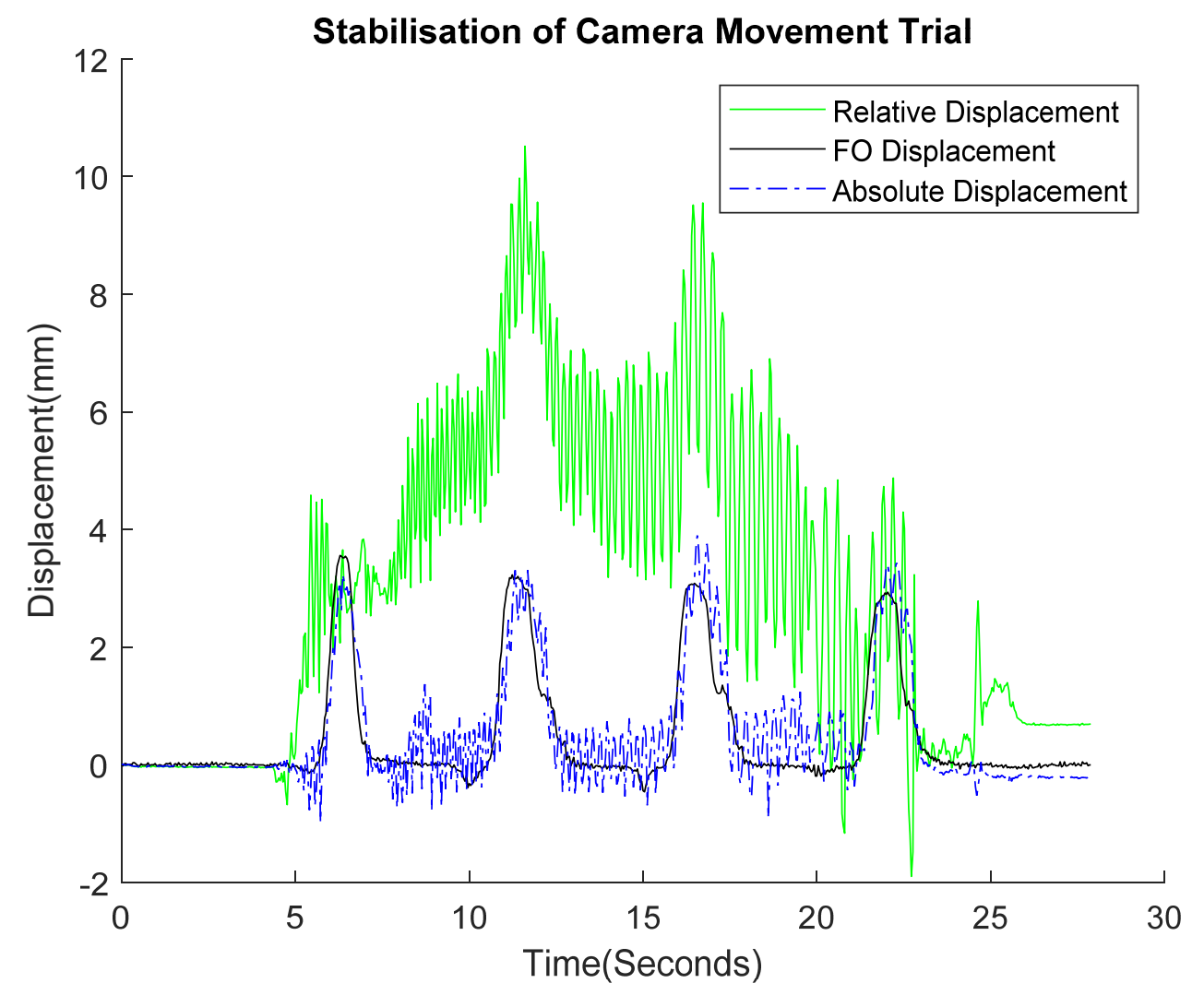

Figure 12 Results from Stabilisation Trial

Table 2 Results from Stabilisation Trial

\begin{tabular}{ccc}
\hline Pixel/mm Scaling & RMSE vs FO for Relative Y & RMSE vs FO for \\
Factor & Displacement & $\begin{array}{c}\text { Absolute Y Displacement } \\
0.1468\end{array}$ \\
$3.4440 \mathrm{~mm}$ & $0.7674 \mathrm{~mm}$ \\
\hline
\end{tabular}

The results presented confirm the effects of camera movement can be counteracted through use of a stable anchor point to calculate absolute displacement at a monitoring location.

\subsection{Field trial 1: Governors Bridge, Belfast}

Constructed in 1973, Governors Bridge is a three-span reinforced concrete beam and slab bridge which crosses the River Lagan to the south of Belfast City. The bridge has an overall length of $62.6 \mathrm{~m}$ and carries two lanes of west bound traffic from the Annandale embankment to the Stranmillis embankment. Figure 13 presents an aerial view of the bridge; the west span was chosen for monitoring and has been highlighted in red. The 
west span of the bridge crosses both the River Lagan and a cycle path. This span was chosen for monitoring as the soffits of the beams were easily accessible as shown in Figure 14. This figure presents a south elevation of the west span of the bridge captured from the cycle path and a cross section through the structure in the east direction.

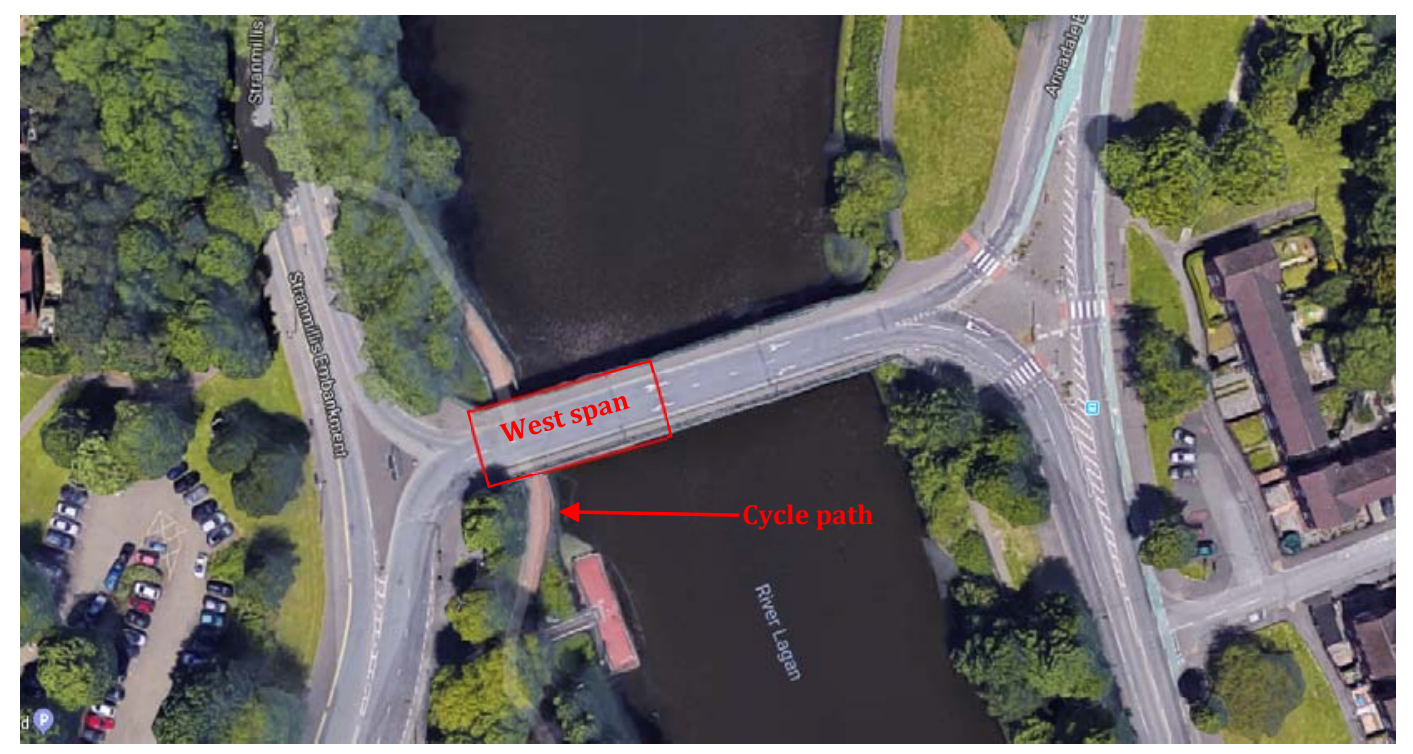

Figure 13: Aerial view of Governors Bridge Belfast

The field test was carried out under normal, non-rush hour, traffic loading on the bridge. Displacement of beam 2 at the location shown in Figure 14 was validated using the FO system used in the laboratory trials in Section 3.1. Data acquisition of the FOS was carried out using a dynamic interrogator at a scanning rate of $25 \mathrm{~Hz}$. Two action cameras were used in the test, one to monitor displacement from the natural feature of the beam and a second camera to identify the load above the deck, the frame rate for both cameras were set at $25 \mathrm{fps}$ to be in sync with the FOS. Action camera 1 (AC1) was located $3.75 \mathrm{~m}$ from the measurement point, action camera 2 (AC2) was used on the bridge deck to provide information on the vehicle types that caused displacement readings. Pixel: mm scaling was carried out using the formula in Equation (2) with a calculated scaling factor of $0.0798 \mathrm{~mm} / \mathrm{pixel}$. 


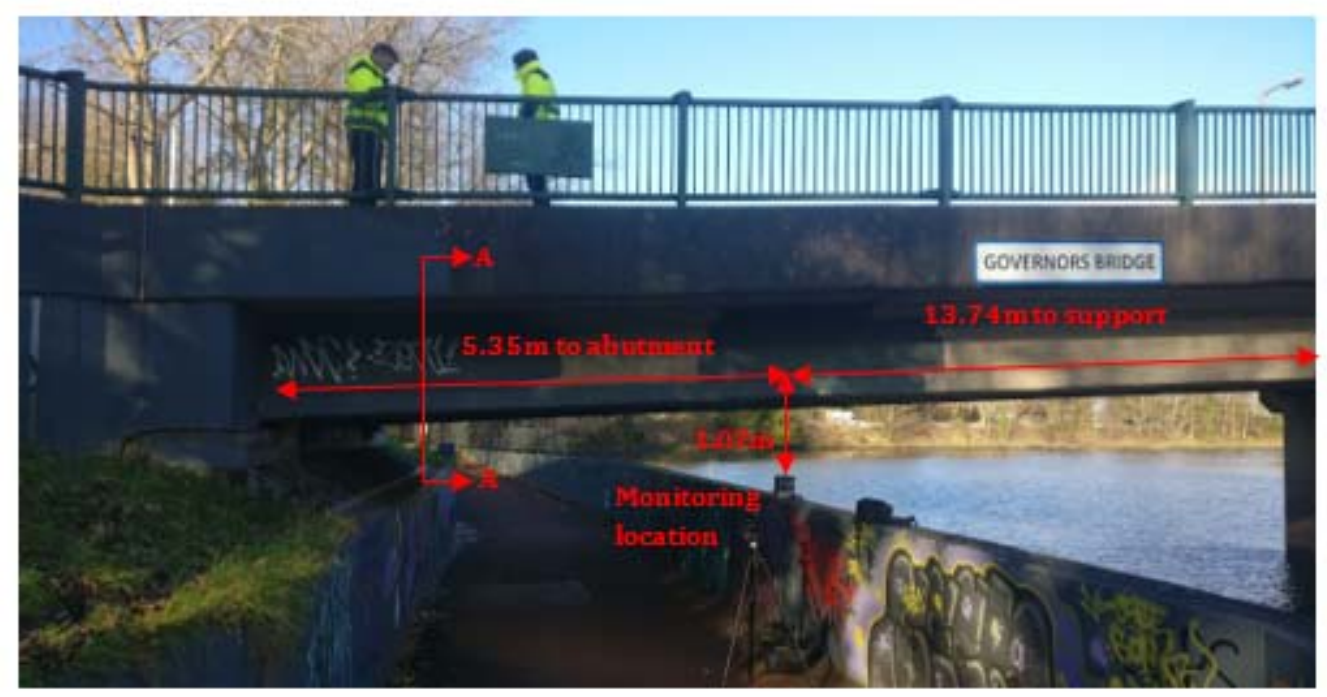

(a) South elevation

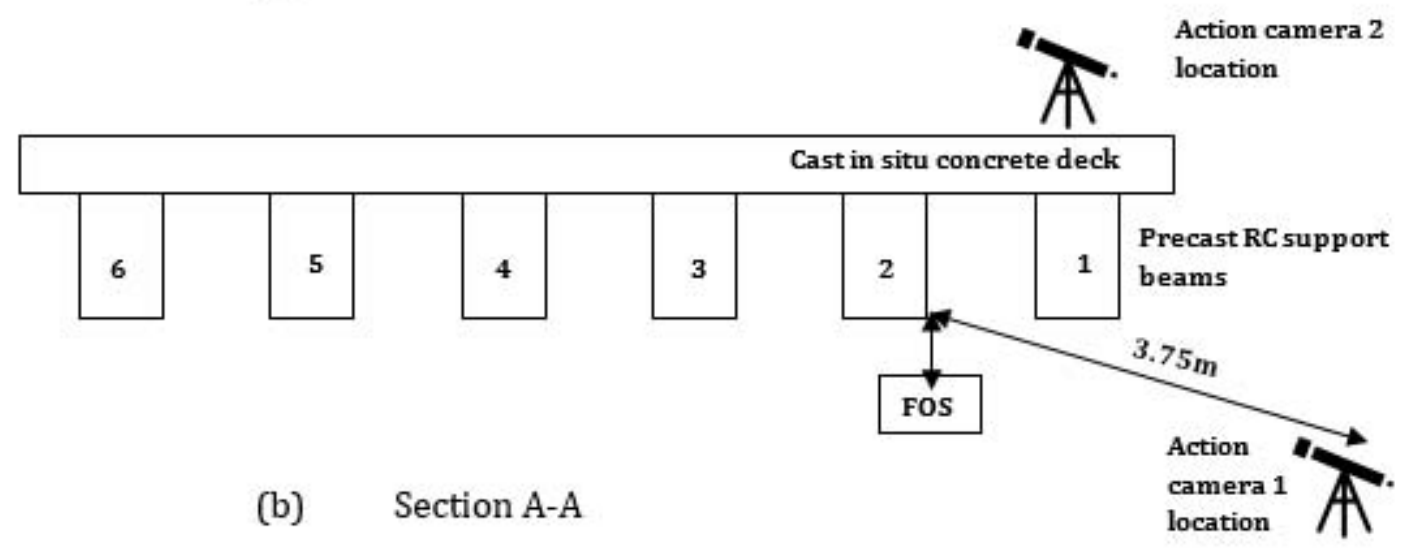

Figure 14 West Span of Governors bridge showing instrumentation locations.

\subsubsection{Results}

The displacement response of the bridge under two live loading events, a coach and truck, is presented in Figure 15 and Figure 16. Beam 2 is located under the south lane meaning that the vehicle position in Figure 15 induced a greater displacement response on the beam compared with Figure 16. The displacement and time histories obtained from the vision sensor and the FO gauge are shown, together with an image of the vehicle. The identified displacements based on the two systems show excellent agreement, with a RMSE of 0.0314 and 0.0321 for the consecutive loading events, in line with the lab trials estimated error, despite the less controlled environment subject to wind and traffic vibrations. Therefore, it was concluded that the same accuracy in displacement measurement can be obtained from the vision sensor as the current state-of-the-art technology; and that the system is suitable for field work. 

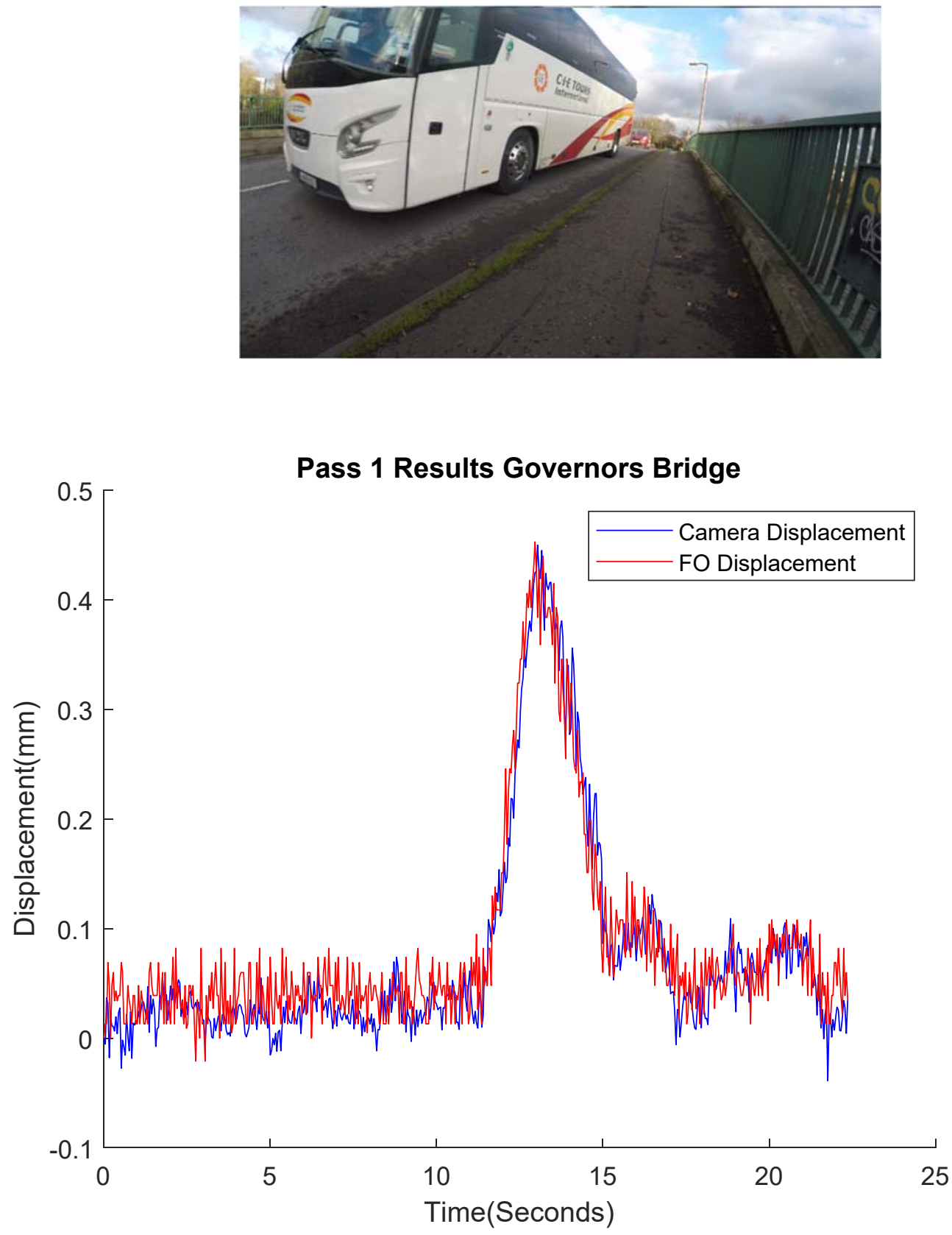

Figure 15: Response of bridge under live loading due to 2 axle Class 3 vehicle in south lane

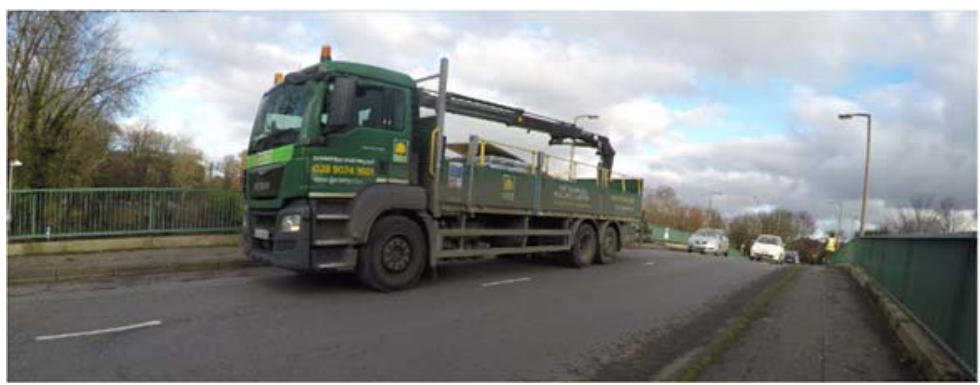




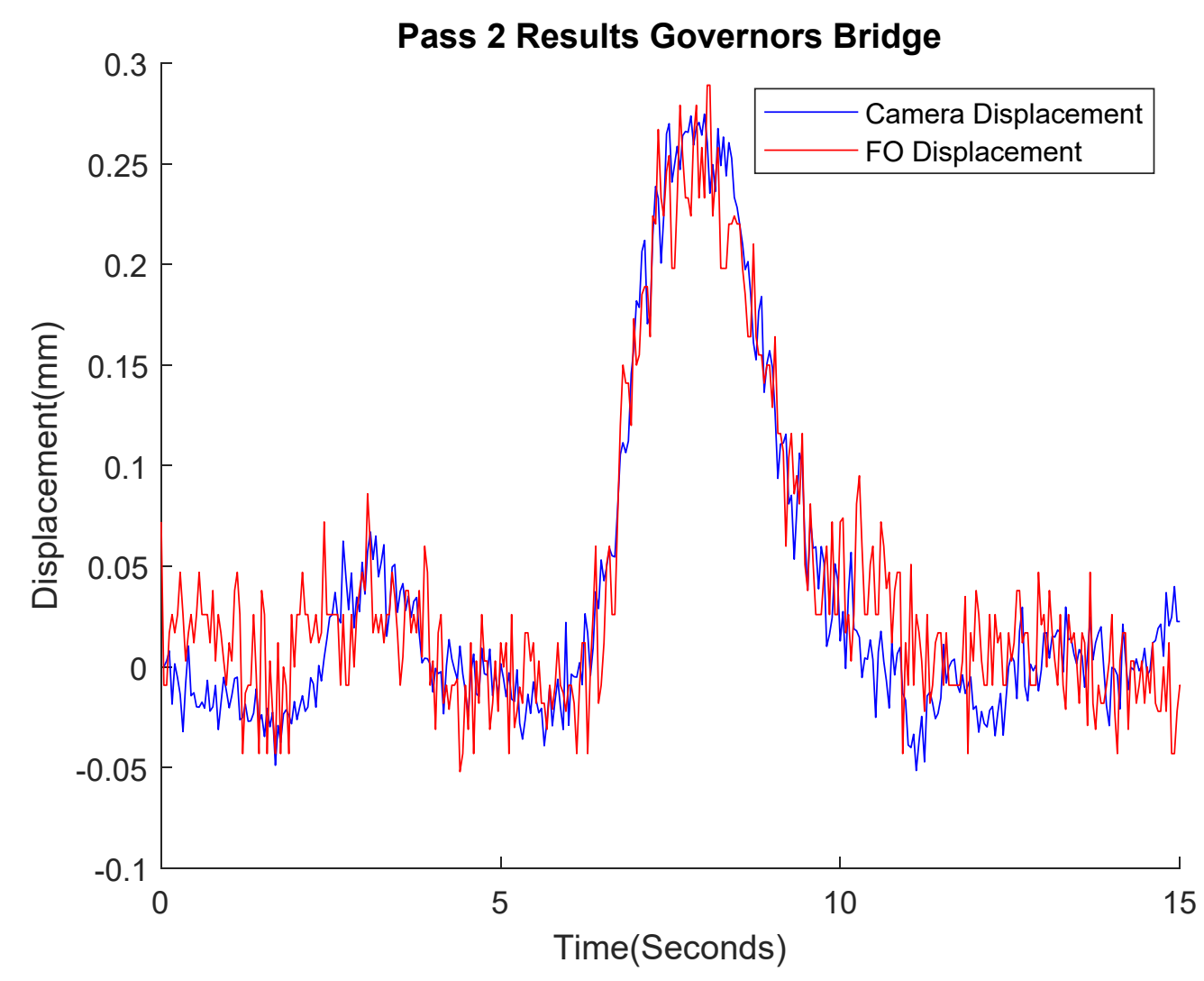

Figure 16: Response of bridge under live loading due to 3 axle Class 5 vehicle in south lane

\subsection{Field Trial 2 - Peace Bridge}

The Peace Bridge (Figure 17) is a self-anchored suspension bridge with a single $96.3 \mathrm{~m}$ suspended central span ('Main Span'), two suspended 63.4m side spans ('east span' and 'west span'), and sections not supported by cables carried by guided supports between the side spans and abutments. At the west end the single section between the support 1 (west abutment) and support 2 is $12.5 \mathrm{~m}$. At the East end sections span $39.4 \mathrm{~m}$ from Support 5 to Support 6 and $37.2 \mathrm{~m}$ from Support 6 to Support 7 (abutment). The bridge is a continuous steel girder, and longitudinal movement, principally due to thermal expansion, is permitted at the supports and abutments. Pylons are at Support 3 and Support 4, where all degrees of freedom are restrained, although small longitudinal movement of $5 \mathrm{~mm}$ is allowed. The details of the design and construction of Peace Bridge, which spans the Foyle River and is a symbol of renewed cooperation between religious communities can be found in the literature[42]. 

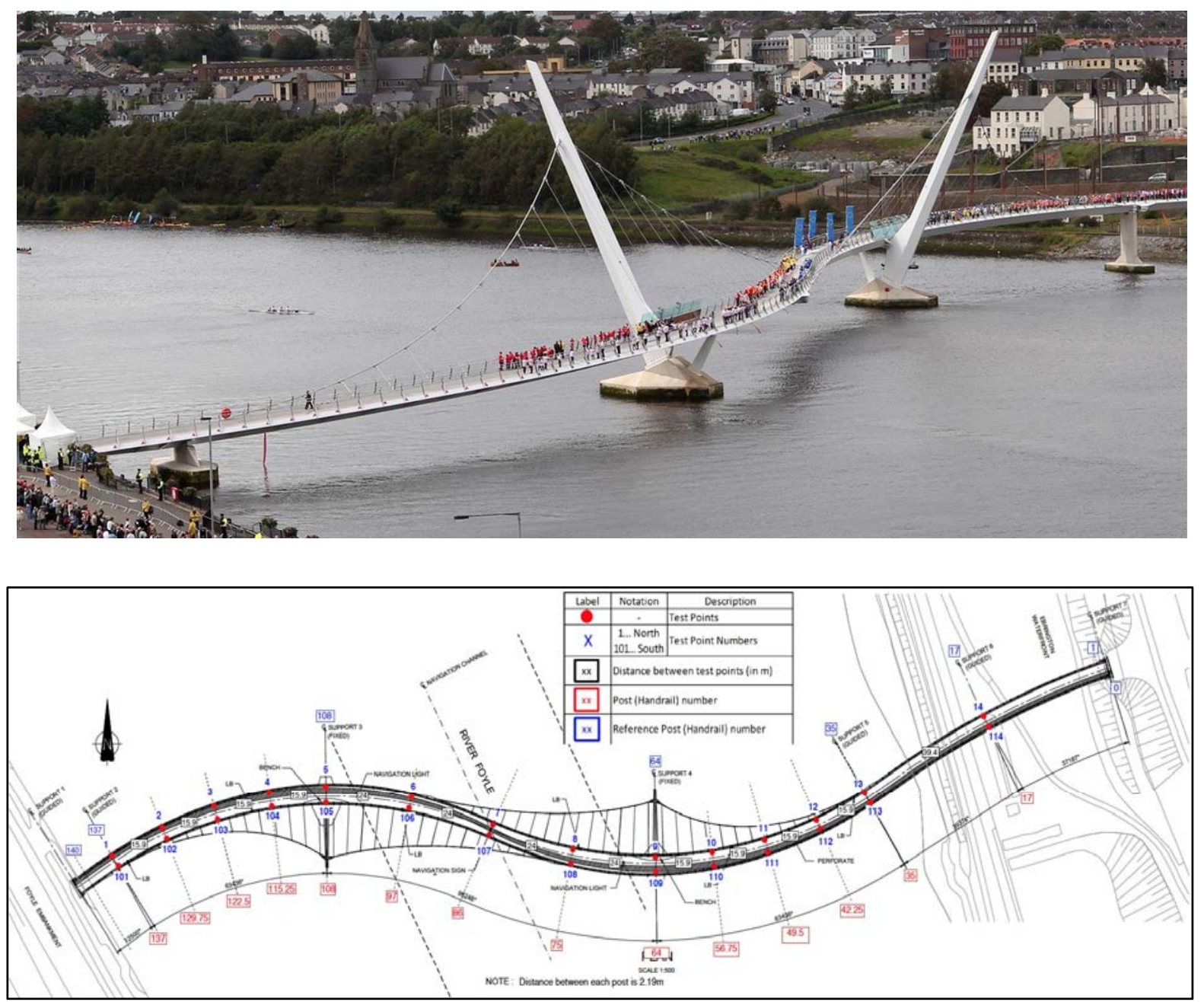

Figure 17: Peace Bridge, plan dimensions and test points for vibration testing (TP's)

In 2016 Full scale Dynamics Ltd (FSDL) in collaboration with Queen's University Belfast (QUB) were commissioned by Transport NI to investigate the dynamic response of the Peace Bridge to crowd loading on the $30^{\text {th }}-31^{\text {st }}$ of October 2016.The Halloween period was chosen to carry out the test as the bridge forms a central element of a large Halloween festival and there are large numbers of pedestrians on the bridge. The Festival was voted the World's Best Halloween Festival by TripAdvisor in 2016. The culmination of this festival was a fireworks display, during which the bridge was temporarily closed. On completion of the display, the bridge was reopened to a one-way flow of pedestrians from west to east. On Sunday $30^{\text {th }}$ October a sequence of ambient vibration measurements was used to characterise the bridge in terms of modal frequencies, modal damping ratios and mode shapes. Based on these measurements two vibration modes were excited to provide further estimates of their modal frequencies and damping ratios. On Monday $31^{\text {st }}$ October the vibration response of the bridge was monitored before and after the fireworks during which vibrations were recorded at times of large uni-directional pedestrian flow. To determine the viability of the camera-based sensor for future monitoring one location was selected for vision-based monitoring and the results were compared to those obtained by the double integration of the vertical accelerations at the same location. 


\subsubsection{Measurement equipment and parameters.}

Vibrations were measured using a set of Honeywell QA-750[43] accelerometers and recorded using a Signalcalc Mobilyzer ('analyser') [44]. A comprehensive array of signal cables was used to connect 14 accelerometers located at various TPs to the analyser, located in a van parked off the footpath below the bridge between Support 6 and Support 7. Figure 18 shows the accelerometers, cabling and acquisition equipment in use. Accelerations were sampled at $51.2 \mathrm{~Hz}$ to provide information in the $0-20 \mathrm{~Hz}$ bandwidth
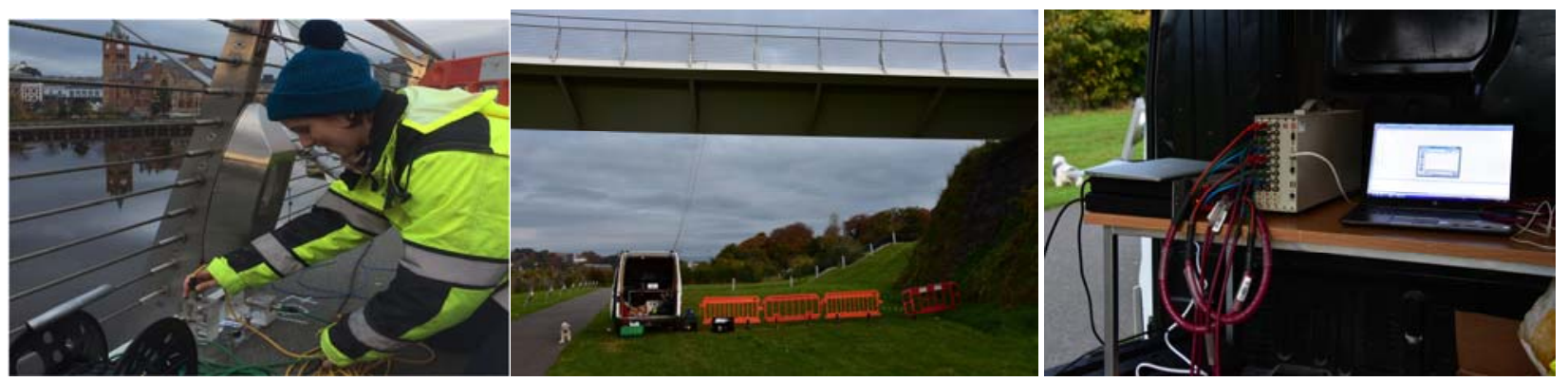

Figure 18: Instrumentation, Function testing QA-740's, van location and analyser.

As shown in Figure 17, the camera was set-up in a tripod on the east bank of the river. TP 112 (Figure 17) was chosen as the location to monitor for vison-based displacements, this represents midspan of the west span. The camera was set up in a matter of minutes compared to several hours required to place and run cables to the accelerometers along the $312 \mathrm{~m}$ footway. The accelerometer array also required mains power for the duration of the testing. The single camera system cannot provide a modal analysis based on simultaneous measurements along the whole length of the bridge. However, it can confirm that the displacements at an individual location are within the allowable limits and be the base for a future multi-camera system for modal analysis. The distance between the camera and the monitoring location was $71.2 \mathrm{~m}$ and the location corresponds to an accelerometer location to provide a ground truth for verification of the readings gathered by the camera. The distance between two handrail posts on the bridge as shown in Figure 21 was used as a reference for eq. (2) and a pixel: mm scaling factor of 3.457 was calculated. The elevation angle between the camera and the monitoring location was approximately $12^{\circ}$. Experimental work by [23] has shown that monitoring angles of less than $15^{\circ}$ do not have a detrimental effect on system performance.

\subsubsection{Measurement summary}

Figure 17 indicates the full set of 28 test points (TPs) for vibration (acceleration) measurements during the two-day exercise. Mode shapes were assembled from a sequence of measurements on the first day with accelerometers set at different combinations of TPs and directions (V, L, Lo):

- Vertical (V): Positive direction upwards.

- Lateral (L): Perpendicular to bridge main axis at TP, positive direction from South side to North side.

- Longitudinal (Lo): Along the bridge axis, positive direction towards the East side. 
On the second day, based on the modal test data, accelerometers were laid out to monitor the bridge response during the heavy pedestrian traffic of the Halloween event. As this paper is focused on the validation of the vision-based displacement monitoring carried out during the crowd loading only this sequence of measurement has been included and is identified as Monit_03 (Figure 19).

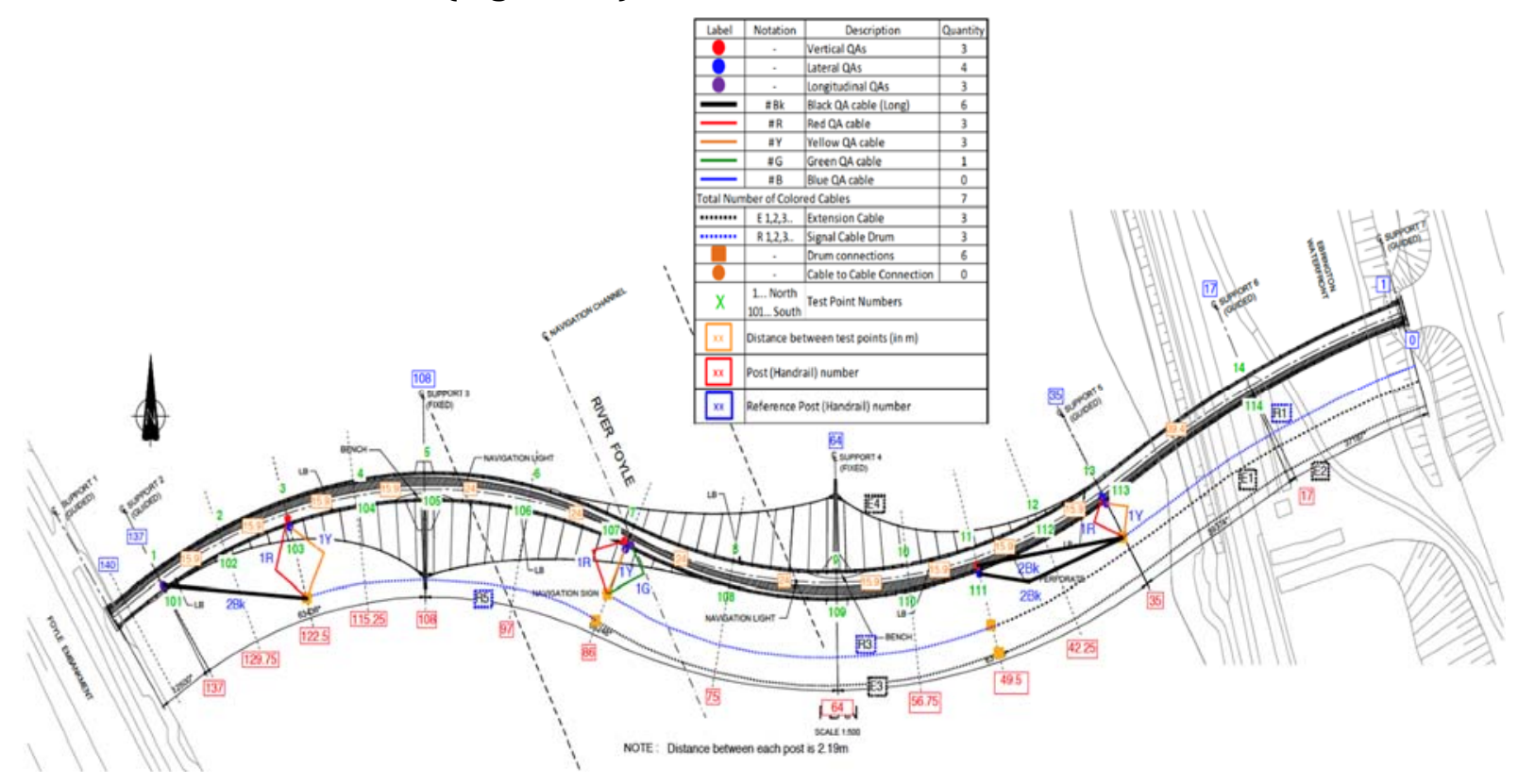

Figure 19 Accelerometer layout for Monit_03

\subsection{Results}

The response of bridge immediately after the fireworks display was chosen as a suitable monitoring period to compare the results, there are significant numbers of pedestrians on the bridge at this time. The bridge was opened to one-way flow of pedestrians from West to East. This happened twice because congestion at the east exit resulted in an accumulation of a large stationary crowd at the first bridge was opening. Pedestrian flow was halted to let this crowd dissipate after which the bridge was reopened, and a large West-East crowd movement developed again. When the West to East flow had started to subside, pedestrians could move from East to West, but the dominant flow remained West-East. It should be noted that for this bridge the dominant dynamic movements were well below the scanning frequency of the camera and therefore temporal aliasing was not an issue. However, if the frequency of dynamic movements are high relative to the scanning frequency/frame rate of the camera the user should be cognisant of potential errors due to temporal aliasing. Camera vibration caused by environmental conditions was removed through image stabilisation [41] using the stationary building in the background of the image as a reference point. The results from the stabilisation processing on a long term video can be seen in Figure 20. 


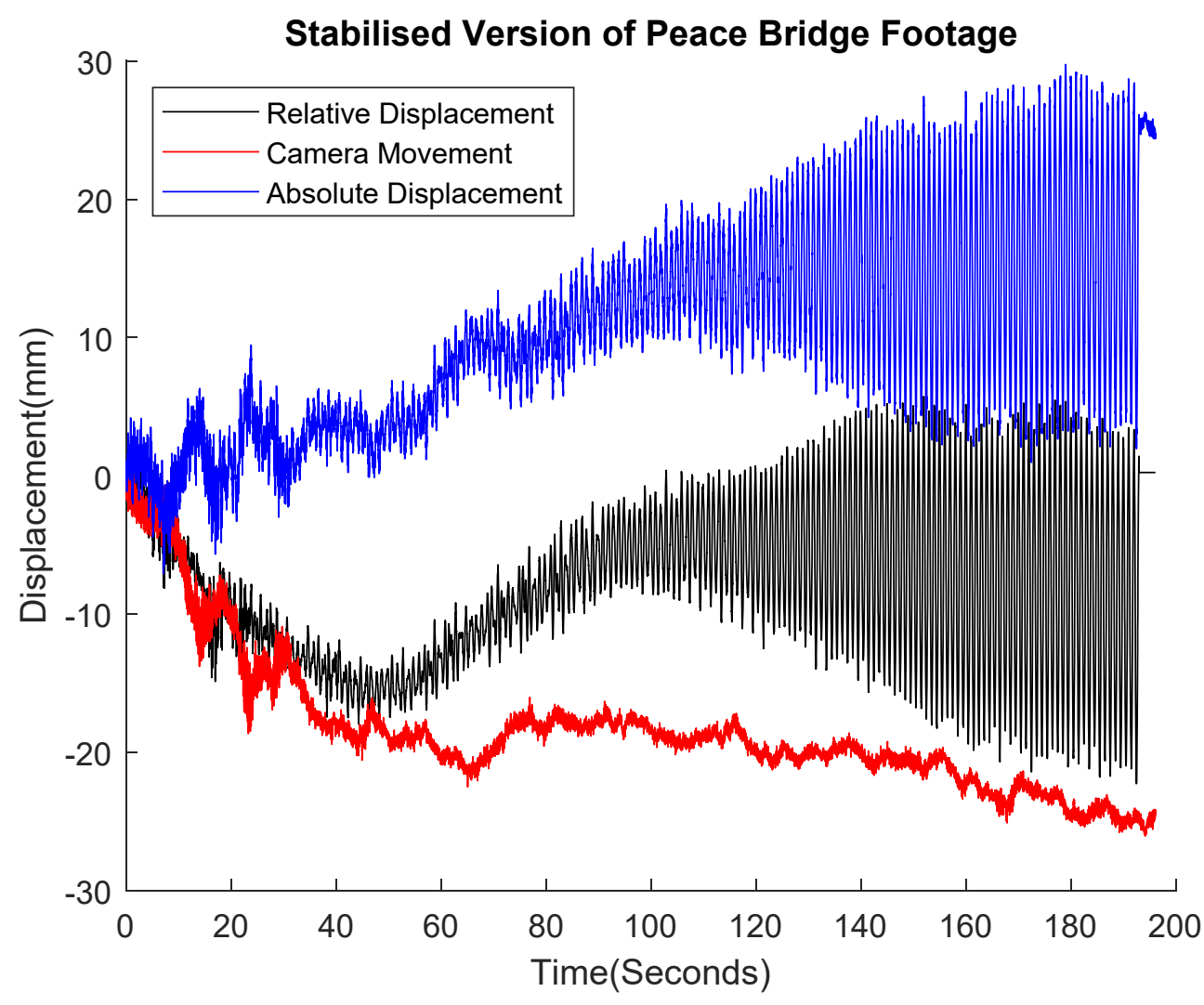

Figure 20 Absolute and Relative Displacement Values for Camera Sensor

The displacements obtained from the double integration of the acceleration signals at location $111 \mathrm{~V}$ and the camera sensor at the same location are presented in Figure 21. The monitoring location is circled in red, and as monitoring was carried out in reduced lighting, a corresponding daylight image has been added for clarity. Again, the displacement measurements achieved from the camera sensor show good correlation with those obtained from the accelerometer. It is clear from the plot that the vision-based displacements do not correspond to the ground truth as accurately as those obtained at Governors Bridge. Given the poor lighting conditions, large monitoring distance (resulting in a minimum displacement resolution of $\sim 3.5 \mathrm{~mm}$ ) and the possible error during integration of the accelerations, the findings are certainly promising for this low cost monitoring system. 

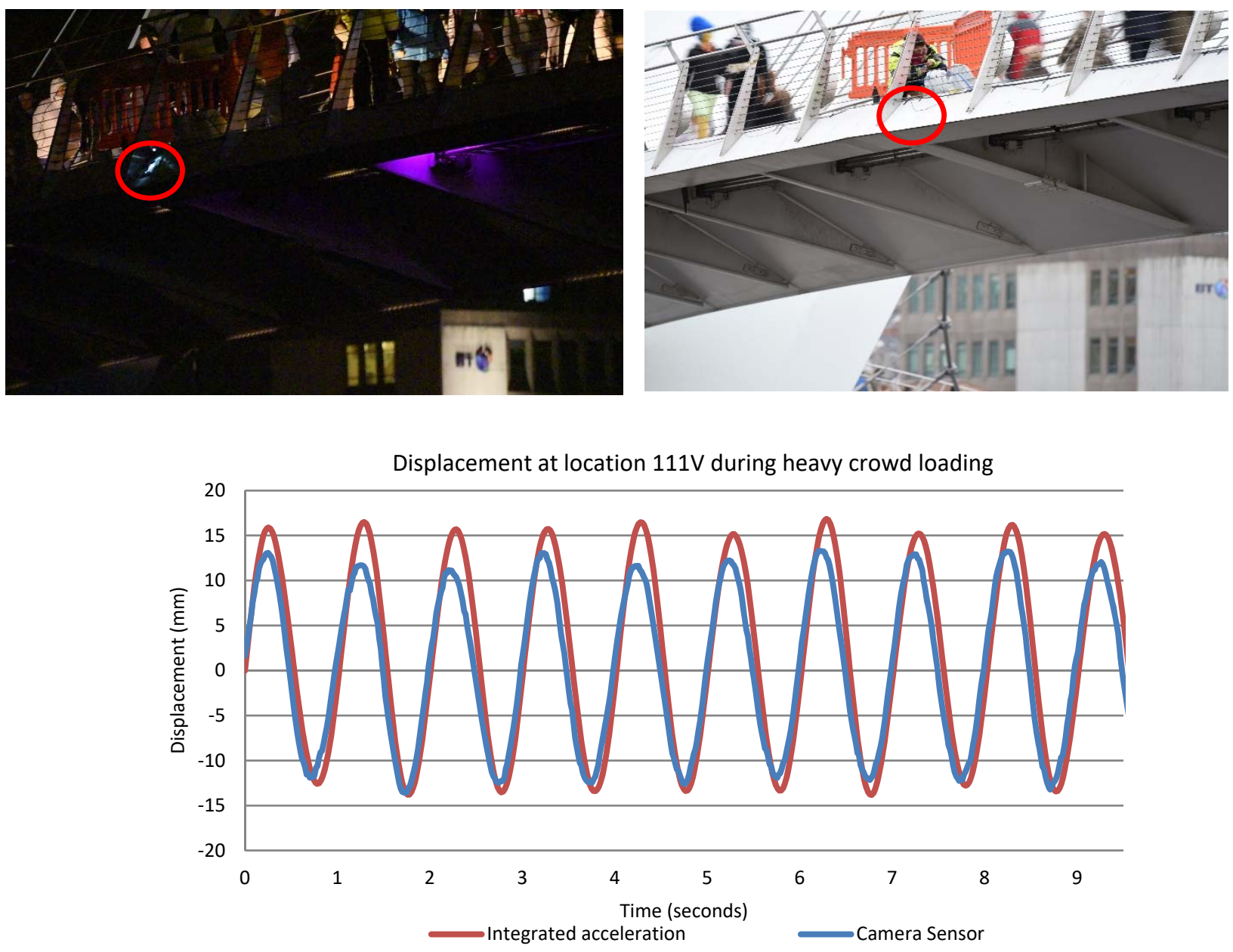

Figure 21 Monitoring location and displacement response to crowd loading

\section{Conclusions}

This study has detailed the development and field evaluation of a low-cost contactless vision system for remote measurement of structural displacements. The system was evaluated through a comprehensive laboratory and field experimentation whereby a commercially available action camera collected images which were compared with highly accurate displacement measurements obtained using a reference measurement system. The following conclusions can be drawn:

During the laboratory experiments the modified action camera and associated displacement algorithms achieved satisfactory agreements with the chosen reference measurement. The system has been confirmed to provide accurate displacement measurements in field environments, overcoming existing limitations in terms of lighting and power supply requirements. The validation of this system in this study facilitates its use for future monitoring of the Peace Bridge and similar structures, displacement measurement using traditional systems may be cost prohibitive. As the system does not require any target in the structure and is fully battery operated and wireless the potential for rapid deployment on rural sites is particularly promising. Further development of this system will involve the synchronization of several cameras to facilitate wireless 
multipoint displacement monitoring of civil infrastructure and full modal dynamic analysis.

\section{Acknowledgements}

The authors wish to express their gratitude for the financial support received from Invest Northern Ireland, The national Science Foundation and Science Foundation Ireland towards this investigation under the US-Ireland Partnership Scheme. They also gratefully acknowledge the Transport NI and the Department of Infrastructure NI for their cooperation and support of this research.

\section{BIBLIOGRAPHY}

[1] D. Lydon, S.E. Taylor, D. Robinson, M. Lydon, D. Hester, Monitoring of Bridges using Computer Vision Methods, in: Civ. Eng. Res. Assoc. Irel., Galway, Ireland, 2016.

[2] B.R. Program, Tech Notes Reliability of Visual Inspection for Highway Bridges , Volume I : Final Report and, Volume II : Appendices, 2003.

[3] M. Lydon, S. Taylor, D. Robinson, C. Doherty, P. Callender, ASSESSMENT OF VARIOUS SENSORS FOR STRUCTURAL HEALTH MONITORING FOR BRIDGE WEIGH - IN - MOTION ( B - WIM ), in: 6 Th Int. Conf. Struct. Heal. Monit. Intell. Infrastruct., Hong Kong, 2013.

[4] D. Inaudi, Cost-Benefits Analysis in SHM Projects Cost-Benefits Analysis in SHM Projects, Proc. Fifth Int. Conf. Struct. Heal. Monit. Intell. Infrastruct. (2011) 1-9.

[5] R. Zaurin, F. Necati Catbas, Structural health monitoring using video stream, influence lines, and statistical analysis, Struct. Heal. Monit. An Int. J. 10 (2011) 309-332. doi:10.1177/1475921710373290.

[6] D.H. Sigurdardottir, B. Glisic, On-site validation of fiber-optic methods for structural health monitoring: Streicker Bridge, J. Civ. Struct. Heal. Monit. 5 (2015) 529-549. doi:10.1007/s13349-015-0123-x.

[7] T. Ojio, C. Carey, E. OBrien, C. Doherty, S. Taylor, Contactless Bridge Weigh-inMotion, J. Bridg. Eng. (2016) 4016032. doi:10.1061/(ASCE)BE.19435592.0000776.

[8] J.J. Lee, M. Shinozuka, A vision-based system for remote sensing of bridge displacement, NDT E Int. 39 (2006) 425-431. doi:10.1016/j.ndteint.2005.12.003.

[9] S.B. Im, S. Hurlebaus, Y.J. Kang, Summary Review of GPS Technology for Structural Health Monitoring, J. Struct. Eng. 139 (2013) 1653-1664. doi:10.1061/(ASCE)ST.1943-541X.0000475.

[10] H.S. Park, H.M. Lee, H. Adeli, I. Lee, A new approach for health monitoring of structures: Terrestrial laser scanning, Comput. Civ. Infrastruct. Eng. 22 (2007) 19-30. doi:10.1111/j.1467-8667.2006.00466.x. 
[11] X.W. Ye, C.Z. Dong, T. Liu, A Review of Machine Vision-Based Structural Health Monitoring: Methodologies and Applications, J. Sensors. 2016 (2016) 1-10. doi:10.1155/2016/7103039.

[12] N. McCormick, J. Lord, Digital image correlation, Mater. Today. 13 (2010) 52-54. doi:10.1016/S1369-7021(10)70235-2.

[13] Z. Xiong, Y. Zhang, A critical review of image registration methods, Int. J. Image Data Fusion. 1 (2010) 137-158. doi:10.1080/19479831003802790.

[14] Z. Wang, H. Kieu, H. Nguyen, M. Le, Digital image correlation in experimental mechanics and image registration in computer vision: Similarities, differences and complements, Opt. Lasers Eng. 65 (2014) 18-27. doi:10.1016/j.optlaseng.2014.04.002.

[15] a M. Wahbeh, J.P. Caffrey, S.F. Masri, A vision-based approach for the direct measurement of displacements in vibrating systems, Smart Mater. Struct. 12 (2003) 785-794. doi:10.1088/0964-1726/12/5/016.

[16] X.W. Ye, Y.Q. Ni, T.T. Wai, K.Y. Wong, X.M. Zhang, F. Xu, A vision-based system for dynamic displacement measurement of long-span bridges: Algorithm and verification, Smart Struct. Syst. 12 (2013) 363-379. doi:10.12989/sss.2013.12.34.363 .

[17] R. Gamache, E. Santini-Bell, Non-intrusive Digital Optical Means to Develop Bridge Performance Information, in: Non-Destructive Test. Civ. Eng., Nantes,France, 2009: pp. 1-6. https://core.ac.uk/download/files/145/21747026.pdf.

[18] M. Malesa, D. Szczepanek, M. Kujawińska, A. Świercz, P. Kołakowski, Monitoring of civil engineering structures using Digital Image Correlation technique, in: EPJ Web Conf., EDP Sciences, 2010: p. 31014. doi:10.1051/epjconf/20100631014.

[19] G.A. Stephen, J.M.W. Brownjohn, C.A. Taylor, Measurements of static and dynamic displacement from visual monitoring of the Humber Bridge, Eng. Struct. 15 (1993) 197-208. doi:10.1016/0141-0296(93)90054-8.

[20] X.W. Ye, C.Z. Dong, T. Liu, Image-based structural dynamic displacement measurement using different multi-object tracking algorithms, Smart Struct. Syst. 17 (2016) 935-956. doi:10.12989/sss.2016.17.6.935.

[21] Y. Fukuda, M.Q. Feng, M. Shinozuka, Cost-effective vision-based system for monitoring dynamic response of civil engineering structures, Struct. Control Heal. Monit. 17 (2010) 918-936. doi:10.1002/stc.360.

[22] M.H. Shih, W.P. Sung, Developing dynamic digital image techniques with continuous parameters to detect structural damage, Sci. World J. 2013 (2013) 453468. doi:10.1155/2013/453468.

[23] J.-W. Park, J.-J. Lee, H.-J. Jung, H. Myung, Vision-based displacement measurement method for high-rise building structures using partitioning approach, NDT E Int. 43 (2010) 642-647. doi:10.1016/j.ndteint.2010.06.009. 
[24] G. Busca, A. Cigada, P. Mazzoleni, E. Zappa, Vibration Monitoring of Multiple Bridge Points by Means of a Unique Vision-Based Measuring System, Exp. Mech. 54 (2014) 255-271. doi:10.1007/s11340-013-9784-8.

[25] M.Q. Feng, Y. Fukuda, D. Feng, M. Mizuta, Nontarget Vision Sensor for Remote Measurement of Bridge Dynamic Response, J. Bridg. Eng. 20 (2015) 04015023. doi:10.1061/(ASCE)BE.1943-5592.0000747.

[26] H. Yoon, H. Elanwar, H. Choi, M. Golparvar-Fard, B.F. Spencer, Target-free approach for vision-based structural system identification using consumer-grade cameras, Struct. Control Heal. Monit. 23 (2016) 1405-1416. doi:10.1002/stc.1850.

[27] H. Yoon, J. Shin, B.F. Spencer, Structural Displacement Measurement Using an Unmanned Aerial System, Comput. Civ. Infrastruct. Eng. 33 (2018) 183-192. doi:10.1111/mice.12338.

[28] GoPro, GoPro - Refurbished HERO4 Black 4K Ultra HD Waterproof Camera, (2016). https://shop.gopro.com/EMEA/refurbished/refurbished-hero4black/CHDNH-B11.html (accessed January 19, 2018).

[29] Back-Bone, Ribcage AIR HERO4 Mod Kit Bundle | BACK-BONE, (2016). https://www.back-bone.ca/product/ribcage-air-hero4-mod-kit/ (accessed January 19, 2018).

[30] Seesense, http://www.seesense.eu/backbone-ribcage/4594143407, (2018).

[31] Computar, E5Z2518C-MP : Manual Iris: Megapixel Varifocal Lenses:

ProductsMegapixel, FA, HD, Varifocal - : Computar, (2016).

https://computar.com/product/1115/E5Z2518C-MP (accessed January 19, 2018).

[32] GoPro App - Desktop + Mobile - Capture, create + share., (n.d.). https://shop.gopro.com/EMEA/softwareandapp/ (accessed January 19, 2018).

[33] V. Argyriou, J.M. Del Rincón, B. Villarini, A. Roche, Image, Video \& 3D Data Registration, John Wiley \& Sons, Ltd, Chichester, UK, 2015. doi:10.1002/9781118702451.

[34] G. Hong, Y. Zhang, Combination of feature-based and area-based image registration technique for high resolution remote sensing image, in: Geosci. Remote Sens. Symp. 2007. IGARSS 2007. IEEE Int., IEEE, 2007: pp. 377-380. doi:10.1109/IGARSS.2007.4422809.

[35] J. Bouguet, Camera Calibration Toolbox for MATLAB, Http://Www.Vision.Caltech.Edu/Bouguetj/Calib_Doc/Index.Html\#Ref. (2015). http://www.vision.caltech.edu/bouguetj/calib_doc/.

[36] T. Khuc, F.N. Catbas, Computer vision-based displacement and vibration monitoring without using physical target on structures, Struct. Infrastruct. Eng. 13 (2017) 505-516. doi:10.1080/15732479.2016.1164729. 
[37] H. Bay, T. Tuytelaars, L. Van Gool, SURF: Speeded Up Robust Features, (n.d.). http://www.vision.ee.ethz.ch/ surf/eccv06.pdf (accessed December 13, 2017).

[38] D.G. Lowe, Object recognition from local scale-invariant features, in: Proc. Seventh IEEE Int. Conf. Comput. Vis., IEEE, 1999: pp. 1150-1157 vol.2. doi:10.1109/ICCV.1999.790410.

[39] C. Tomasi, T. Kanade, Detection and Tracking of Point Features, Carnegie Mellon Univ. Tech. Rep. (1991) 91-132. http://www.lira.dist.unige.it/teaching/SINA/slides-current/tomasi-kanadetechreport-1991.pdf.

[40] P.H.S. Torr, A. Zisserman, MLESAC: A new robust estimator with application to estimating image geometry, Comput. Vis. Image Underst. 78 (2000) 138-156. doi:10.1006/cviu.1999.0832.

[41] Video Stabilization Using Point Feature Matching - MATLAB \& Simulink Example, (n.d.). https://uk.mathworks.com/help/vision/examples/video-stabilizationusing-point-feature-matching.html (accessed January 19, 2018).

[42] P. Brown, K. Kuhendran, J. Marks, Peace Bridge, Londonderry: design and construction, Proc. Inst. Civ. Eng. - Bridg. Eng. 168 (2015) 163-172. doi:10.1680/bren.14.00004.

[43] Honeywell QA-750 Accelerometer, (n.d.). https://aerospace.honeywell.com/ /media/aerospace/files/brochures/accelero meters/q-flexqa-750accelerometer_bro.pdf (accessed January 19, 2018).

[44] SignalCalc - Mobilyzer, Dynamic Signal Analyzers - Data Physics Corporation, (n.d.). http://www.dataphysics.com/products-and-solutions/dynamic-signalanalyzers-signalcalc/signalcalc-mobilyzer.html (accessed January 19, 2018). 